\title{
A COMPREHENSIVE PERFORMANCE EVALUATION AND RANKING METHODOLOGY UNDER A SUSTAINABLE DEVELOPMENT PERSPECTIVE
}

\author{
Li-Chang HSU ${ }^{1}$, Shang-Ling $\mathrm{OU}^{2}$, Yih-Chang $\mathrm{OU}^{3}$ \\ ${ }^{1,3}$ Department of Finance, Ling Tung University, 1 Ling Tung Road, Nantun, \\ Taichung, 40852 Taiwan, R.O.C. \\ ${ }^{2}$ Department of Agronomy, National Chung Hsing University, 250 KuoKuang Rd., \\ Taichung, 40227 Taiwan, R.O.C. \\ E-mails: ${ }^{1}$ lchsu@teamail.ltu.edu.tw; ${ }^{2}$ slou@dragon.nchu.edu.tw; \\ 3ycou@teamail.ltu.edu.tw (corresponding author)
}

Received 13 June 2013; accepted 20 September 2013

\begin{abstract}
Under industry globalization and the intensely competitive environment, a company's competitiveness must constantly be upgraded in order to achieve the goal of sustainability. Therefore, the correct and valid evaluation of companies' sustainable performance has become an important issue. The main purpose of this study is to discuss and establish a sustainable performance evaluation criteria and model for companies. First, the measurements of companies' financial, credit risk, environmental and social responsibility are integrated to create sustainable business performance evaluation criteria. Then, we integrate grey relational analysis and an improved TOPSIS method to construct a sustainable performance evaluation model for companies. In order to verify the findings of this study, we adopt Taiwan's high-tech listed companies as the research object to explore sustainable operating performance and ranking in 2011. The empirical results will help companies to build future business strategies and can also be used as an important reference for investor and bank credit auditing.
\end{abstract}

Keywords: credit risk, environmental, social responsibility, sustainable performance evaluation, grey relational analysis, TOPSIS method.

JEL Classification: C44, D81, L25, Q56.

\section{Introduction}

In recent years, high-tech companies face the challenges of global competition and a rapidly changing operating environment. To pursue the goal of sustainable development, they need to establish an objective, impartial and convenient performance evaluation model. More reliable performance evaluation results will help company management to understand their own operating conditions and whether or not resources are being used effectively, and also help to develop future resource allocation and targets.

Traditionally, company's operating results are reflected in financial statements, which provide information for measuring operating performance. While financial ratios pro- 
vide a good indication of a company's financial status, they offer one-sided assessment. As a result, investors and authorities cannot get the overall assessment results. Therefore, financial ratios cannot provide a complete explanation of a company's operating performance.

When only using financial ratios to assess a company's operating performance, the company may still fall into an operating crisis. Therefore, since the 2008 financial crisis, companies' risk awareness and control have gradually increased. For investors, a company's credit status is also related to the conduct of pricing investment and financing decisions. Within financial markets, credit rating has been listed as an important reference for credit risk assessment. Because credit rating may reflect the performance of a company, and is a comprehensive credit risk indicator, it can also be regarded as an indicator for assessing a company's operating performance.

Companies in the pursuit of profit produce a lot of pollution that is not conducive to social and environmental development. And indeed, environmental and social contributions help a company's business, bring operational benefits to the company, and also serve as a source of competitiveness for the future development. In recent years, the banking industry also acts in accordance with the Equator Principles, the integration of environmental criteria and social responsibility in their lending decisions. This has made the assessment of a company's sustainable capacity an important reference for credit reviews. Therefore, properly evaluating a company's sustainability performance has become an important issue.

Gamble (1989) mentioned that performance evaluation should include both financial and non-financial measures. Up to now, there is no reliable literature that explains how to select the appropriate criteria for evaluating the corporate sustainability performance of a company. Therefore, the main purpose of this study is to establish a sustainable performance evaluation model by integrating financial and non-financial criteria to assess companies' sustainability performance.

Many evaluation criteria affect a company's sustainable performance. These criteria sometimes come into conflict with each other, making it difficult to find a way to satisfy all the criteria at the same time. Through the multiple criteria decision making (MCDM) method, a compromise solution can be reached between conflicting assessment criteria to assist decision makers in the decision-making process. We use a number of evaluation indicators to evaluate the sustainable performance of different companies and make comparisons between different companies, so MCDM is a good choice for this study.

Behzadian et al. (2012) mentioned that the TOPSIS method is a well-known traditional MCDM method, and has received much interest from researchers and practitioners. Eshlaghy and Kalantary (2011) pointed out that although the TOPSIS method is a powerful technology, it has certain weaknesses. Ozturkoglu and Turker (2013) indicated the TOPSIS method can be widely applied to both science and management area. M. K. Çetin and E. I. Çetin (2010) mentioned that the financial performance evaluation of companies is a type of MCDM problem. Therefore, this study uses the TOPSIS method to evaluate the sustainable performance of companies. 
TOPSIS, which was first developed by Hwang and Yoon in 1981 as a ranking methodology, has been used for many real-world applications in science and engineering. The traditional TOPSIS uses full implementation of attribute information, provides a cardinal ranking of alternatives, and does not need attribute preferences to be completely independent. To use this technique, attribute values must be numeric, monotonically decreasing or increasing, and have commensurable units (Yoon, Hwang 1995). In order to overcome the shortcomings of the traditional TOPSIS method, this study proposes a modified TOPSIS method for the sustainable performance evaluation of companies.

In order to verify the applicability of the modified TOPSIS method proposed here, we take Taiwan's listed high-tech companies as an example. By the modified TOPSIS method, we construct a sustainable performance assessment of the decision-making model to conduct a comprehensive evaluation. Thus, the contribution of this study is twofold. First, we combine financial ratios, risk, environment and corporate social indicators to establish a comprehensive sustainable evaluation criterion. Second, we have established a modified TOPSIS method to overcome the shortcomings of the traditional model, and constructed a sustainable performance evaluation decision making model to conduct comprehensive evaluations.

\section{Literature review of performance evaluation and ranking studies}

Studies of the companies' operating performance in the past have mostly concentrated on financial performance evaluation and ranking. For example, Alam et al. (2011) evaluated the financial performance of Pakistani leasing companies between the years 2008 and 2010 via financial ratio analysis. Cheng et al. (2012) used the fuzzy integral and ordered weight average methods to evaluate the financial performance of the semiconductor industry. Yalçin et al. (2012) applied fuzzy MCDM methods for financial performance evaluation of the Turkish manufacturing industry.

However, the traditional evaluation of financial performance is not an effective or comprehensive measure. Choi and Mueller (1992) mentioned that performance evaluation should consider both financial and non-financial parameters. Therefore, in addition to financial performance criteria, many researchers have also integrated non-financial performance criteria to make a more comprehensive assessment of companies' performance. For example, Seçme et al. (2009) used the fuzzy analytic hierarchy process and TOPSIS methods to rank banks. The results show that not only financial performance but also non-financial performance should be taken into account in a competitive environment.

However, from the company perspective, sustainable development takes into account the environment, ecology and resources in the pursuit of the sustainable management of the company. Elkington (1997) proposed the triple bottom line theory, i.e., a company's performance evaluation should include the company's economic, environmental and social performance indicators. Companies should publish financial, environmental and social performance reports. Comprehensive assessment of a company's performance can be carried out using these three types of reports. Therefore, in order to achieve the 
sustainable performance evaluation of company, in addition to considering financial performance criteria, we must also consider the non-financial performance, such as the measure of environment and corporate social responsibility (CSR), in order to obtain a comprehensive assessment.

\section{The evaluation criteria of a company's sustainable performance}

\subsection{Criteria for financial performance}

Financial ratio analysis is commonly used as a financial performance analysis method. It requires the use of the same industry and the same ratio to make comparisons. Therefore, this study only takes Taiwan's listed high-tech companies as the research object. When measuring a company's financial performance, up to now, there is no reliable theory that explains how to select the appropriate financial ratios as indicators for evaluation. Therefore, this study according to Hsu (2014), financial ratios can be classified into following three categories: operating ability, solvency and profitability, 22 financial ratios were selected (Table 1).

Table 1. The financial indicators on three categories

\begin{tabular}{ll}
\hline \multicolumn{1}{c}{ Category } & \multicolumn{1}{c}{ Financial ratios } \\
\hline $\begin{array}{l}\text { Operating } \\
\text { ability }\end{array}$ & $\begin{array}{l}\text { Total assets turnover ratio (O1), Accounts receivable turnover (O2), Inventory } \\
\text { turnover (O3), Fixed assets turnover (O4), Turnover of networth (O5), Days- } \\
\text { A/R turnover (O6), Days-inventory turnover (O7) }\end{array}$ \\
\hline Solvency & $\begin{array}{l}\text { Cash flow adequacy ratio (S1), Cash reinvestment ratio (S2), Current ratio (S3), } \\
\text { Quick ratio (S4), Long-term capital ratio (S5), Times interest earned (S6), Oper. } \\
\text { income/Capital (S7), Pre Tax Income/Capital (S8), Liabilities (S9) }\end{array}$ \\
\hline Profitability & $\begin{array}{l}\text { Return on assets (P1), Return on equity (P2), Profit margin (P3), Operating } \\
\text { margin (P4), Net profit margin (P5), Earnings per share (P6) }\end{array}$ \\
\hline
\end{tabular}

\subsection{Criteria for risk assessment}

A company credit risk assessment reflects credit rating agencies' assessment of the company's overall credit risk and debt fulfillment. The main reason is the general investing public may not have a financial background, making it difficult for them to read financial information.

In Taiwan, in 1991, the Taiwan Economic Journal (TEJ) began to build a credit risk indicator mechanism. It covers the credit risk of the banking sector based on three causes: accounting quality, industry prospects, and operating risk factors and credit ratings for the listed companies and public companies. Based on these factors, the TEJ established the Taiwan Corporate Risk Index (TCRI). Lu (2012) mentioned that the TCRI is a good credit risk proxy for companies in Taiwan. Therefore, this study uses TCRI as the company's credit risk measurement indicator.

\subsection{Criteria for company's sustainable development performance}

In recent years, the Taiwanese government has encouraged and supported more listed companies in voluntary disclosing CSR reports. The disclosure of CSR reports can 
increase the transparency of corporate governance, which enables stakeholders to understand the social, economic and environmental impact of a company's operation. Arshad et al. (2012) showed that a significant positive relationship exists between the extent of CSR information disclosure and corporate performance. Ratanajongkol et al. (2006) used the number of words used to measure the level of CSR and examine the extent and nature of the CSR practices of the 40 companies in Thailand. Therefore, we use the number of words disclosed in CSR reports as the measure of CSR disclosure (CSRD).

Suttipun and Stanton (2012) used the annual reports of 75 listed companies in Thailand to test the relationships between the amount of environmental disclosure and a number of company characteristics. Therefore, this study uses the total number of words in the content of environmental information disclosure in annual reports as a measure of the degree of environmental information disclosure (EID).

More investment in environmental pollution control research can increase a company's emphasis on environmental quality. Environmental protection expenditure is an indicator of whether a company places great emphasis on environmental protection. Therefore, this study uses environmental intensity $(\mathrm{EI}=$ Environmental protection expenditures / Sales) as a measure of environmental performance.

As companies face increasing competition in the market, innovative research drives companies forward. This type of research is the foundation for developing sustainability. In this study, we consider high-tech industries facing a high degree of competition and significantly shortened life cycles. Therefore, developing sustainable management is an important policy option resulting from R\&D innovation activities. Suh et al. (2013) used R\&D intensity to measure innovation capability and to investigate the effects of European firms' innovative capabilities and experience on their acquisition performance. Therefore, this study uses R\&D intensity (RDI $=$ R\&D expenditures / Sales) as a measure of companies' innovation capability.

\section{Method}

\subsection{Grey relational analysis}

The GRA can be normalized based on the characteristics of the data, which can be divided into three types (Hsu 2014):

(1) the-larger-the-better

$$
x_{i j}^{*}=\frac{x_{i j}-\min _{i} x_{i j}}{\max _{i} x_{i j}-\min _{i} x_{i j}},
$$

where $x_{i j}$ is the original sequence, $\max _{i} x_{i j}$ is the largest value of $x_{i j}, \min _{i} x_{i j}$ is the smallest value of $x_{i j}$,

(2) the-smaller-the-better

$$
x_{i j}^{*}=\frac{\max _{i} x_{i j}-x_{i j}}{\max _{i} x_{i j}-\min _{i} x_{i j}},
$$


(3) the-nominal-the-better

$$
x_{i j}^{*}=\frac{\left|x_{i j}-x_{o b j}\right|}{\max _{i} x_{i j}-x_{o b j}},
$$

where $\max x_{i j} \geq x_{i j} \geq \min x_{i j}, x_{o b j}$ is the target value of $x_{i j}$.

The globalized GRA is ${ }^{i}$ described below:

Step 1. Calculate the grey relational coefficient:

$$
\gamma\left(x_{i}(k), x_{j}(k)\right)=\frac{\min _{i} \min _{j} \Delta_{\min }+\varsigma \max _{i} \max _{j} \Delta_{\max }}{\Delta_{i j}(k)+\varsigma \min _{i} \min _{j} \Delta_{\min }},
$$

where $\Delta_{i j}(k)=\left|x_{i}(k)-x_{j}(k)\right|, k=1,2, \cdots, n, i=1,2, \cdots, m, j \in i, \varsigma$ is a distinguishing coefficient, $\varsigma \in[0,1]$. Generally, the $\varsigma$ is taken as 0.5 .

Step 2. Determining the grey relational matrix.

Suppose that there are $m$ reference sequences and $n$ comparison sequences, the grey relational matrix can be established as follows:

$$
R_{m \times m}=\left[\begin{array}{cccc}
\Gamma_{11} & \Gamma_{12} & \cdots & \Gamma_{1 m} \\
\Gamma_{21} & \Gamma_{22} & \cdots & \Gamma_{2 m} \\
\vdots & \vdots & \ddots & \vdots \\
\Gamma_{m 1} & \Gamma_{m 2} & \cdots & \Gamma_{m m}
\end{array}\right]_{m \times m}
$$

where the grey relational grade $\Gamma_{i j}=\Gamma\left(x_{i}, x_{j}\right)=\sum_{k=1}^{n} \beta_{k} \gamma\left(x_{i}(k), x_{j}(k)\right)$, represents the degree of correlation between the reference and comparison sequences. $\beta_{k}$ represents the weighting value of the $k$ th indicator, and $\sum_{k=1}^{n} \beta_{k}=1$.

\subsection{The proposed modified TOPSIS method}

For the purpose of improving the three shortcomings of the traditional TOPSIS method, this article proposes a modified TOPSIS method. The details are described below.

\subsubsection{The normalization method}

In the traditional TOPSIS, the vector normalization method has been utilized. Unfortunately, it makes no difference when normalizing between positive attributes and negative attributes. The different methods used by the traditional TOPSIS in constructing a standardized decision matrix have significant impact on the final assessment results. Therefore, we used the Minimum-Maximum based normalization function (Zeng et al. 2004) to improve the normalization method in the traditional TOPSIS method. The normalization functions are described as follows: 1) for the positive attributes (i.e. thelarger-the-better), the functions are the same as those in Eq. (1). 2) For the negative attributes (i.e. the-smaller-the-better), the functions are the same as those in Eq. (2). 


\subsubsection{The weighted Euclidean distance measure}

Olson (2004) mentioned that when the TOPSIS method is used to calculate the separation, the m-dimensional Euclidean distance is not the most appropriate. Shyur and Shih (2006) mentioned the shortcoming of TOPSIS is that the calculation of the separation doubles the attributes' weights. To overcome this problem, we adopt the weighted Euclidean distance to measure the distance. The weighted Euclidean distance used in this study is defined as follows

$$
\begin{aligned}
& d_{i}^{+}=\left\{\sum_{j=1}^{n} w_{j}\left(v_{i j}-v_{j}^{+}\right)^{2}\right\}^{\frac{1}{2}}, i=1,2, \ldots, m, \\
& d_{i}^{-}=\left\{\sum_{j=1}^{n} w_{j}\left(v_{i j}-v_{j}^{-}\right)^{2}\right\}^{\frac{1}{2}}, i=1,2, \ldots, m .
\end{aligned}
$$

\subsubsection{The improved method for weight determination of the evaluating indicators}

This study uses a combination weighting method, combined with the grey entropy method, grey relational matrix method, and CRITIC method to determine the weight, as described below.

\section{(1) Grey entropy method}

The grey entropy method is described in brief as follows:

Step 1. Construct a decision matrix $B$. When there are $m$ alternatives and $n$ evaluation indicators in a MCDM problem, we can construct a decision matrix:

where $i=1,2, \cdots, m, j=1,2, \cdots, n$.

$$
B=\left[\begin{array}{cccc}
x_{11} & x_{12} & \cdots & x_{1 n} \\
x_{21} & x_{22} & \cdots & x_{2 n} \\
\vdots & \vdots & \ddots & \vdots \\
x_{m 1} & x_{m 2} & \cdots & x_{m n}
\end{array}\right]_{m \times n},
$$

Step 2. Normalize the decision matrix using the Eqs. (1)-(3). The normalized decision matrix $R$ :

$$
R=\left[\begin{array}{cccc}
x_{11}^{*} & x_{12}^{*} & \cdots & x_{1 n}^{*} \\
x_{21}^{*} & x_{22}^{*} & \cdots & x_{2 n}^{*} \\
\vdots & \vdots & \ddots & \vdots \\
x_{m 1}^{*} & x_{m 2}^{*} & \cdots & x_{m n}^{*}
\end{array}\right]_{m \times n}
$$

Step 3. Calculation of the entropy of each evaluation criteria $\left(e_{j}\right)$ :

$$
e_{j}=\frac{1}{0.6487 m} \sum_{i=1}^{m} W_{e}\left(x_{i j}^{*} / B_{j}\right)
$$

where $e_{j}$ represents the entropy value of the $j$ th evaluation criteria,

$W_{e}=x e^{(1-x)}+(1-x) e^{(1-x)}-1, B_{j}=\sum_{i=1}^{m} x_{i j}^{*}, j=1,2, \ldots, n$. 
Step 4. Calculation of the weight of each evaluation criteria $\left(w_{j}\right)$ :

where $E=\sum_{j=1}^{n} e_{j}$.

$$
w_{j}=\frac{\left[\left(1-e_{j}\right) /(n-E)\right]}{\sum_{j=1}^{n}\left[\left(1-e_{j}\right) /(n-E)\right]},
$$

\section{(2) Grey relational matrix method}

The steps of the grey relational matrix based on globalized GRA are described as follows:

Step 1. According to Eqs. (1)-(5), obtain grey correlation matrix $R$.

Step 2. Calculate the eigenvalue $\lambda_{1}, \lambda_{2}, \cdots, \lambda_{m}$ from the grey relational matrix.

Step 3. Calculate the eigenvectors of a matrix $P$, where $P^{-1} R P=\operatorname{diag}\left\{\lambda_{1}, \lambda_{2}, \cdots, \lambda_{m}\right\}$.

Step 4. Choose the largest eigenvector corresponding to the largest value $\lambda_{\max }$, and the weight is the eigenvector of each corresponding element.

\section{(3) CRITIC method}

The steps of the CRITIC method are as follows (Diakoulaki et al. 1995):

Step 1. Establish the normalized sequence.

Step 2. Calculate the normalized values to the amount of information according to the $C_{k}$ values:

$$
C_{k}=\sigma_{k} \sum_{j=1}^{n}\left(1-r_{k j}\right), k=1,2, \cdots, n,
$$

where $\sigma_{k}$ is the standard deviation of criterion $k, r_{k j}$ is the correlation coefficient between criteria $k$ and $j$.

Step 3. Calculate the objective weight of criterion $k\left(w_{k}\right)$ :

\section{(4) Combined weight method}

$$
w_{k}=\frac{C_{k}}{\sum_{k=1}^{n} C_{k}} \text {. }
$$

We used Spearman rank correlation coefficient objective weighting method as the combined weight method of the three objective weights. Spearman's rank correlation coefficient weighting method can be divided into the following four steps:

Step 1. Calculating Spearman's rank correlation coefficient. This coefficient is defined as:

$$
\rho_{i k}=1-\frac{6 \sum_{j=1}^{n}\left(w_{i j}-w_{k j}\right)^{2}}{n(n-1)(n+1)}, i, k=1,2, \cdots, m, j=1,2, \cdots, n,
$$

where $\rho_{i k}$ is the Spearman's rank correlation coefficient between the $i$ th weighting method and $k$ th, $w_{i j}$ is the $i$ th method for calculating the weight of the $j$ th indicators and $w_{k j}$ is the $k$ th method for calculating the weight of the $j$ th indicators. 
Step 2. Find the relative consistency of the highest weighting method. First, find out the maximum value of $\rho_{i k}, \rho_{U V}=\max \left\{\rho_{i k}\right\}$. Then, compare the weight methods $U$ and $V$ and other Spearman's rank correlation coefficient values and select the largest. We assume that method $U$ will be selected. That is, among all the weight methods, the method $U$ consistency has the highest weight values. Together, the other weighting methods and method $U$ of the Spearman's rank correlation coefficient can construct vector $\rho_{U}=\left(\rho_{1 U}, \rho_{2 U}, \ldots, \rho_{n U}\right)$.

Step 3. Obtain the weight vectors after normalization. We get the normalized weight vectors $(W)$ via normalization $\rho_{U}$ :

$$
W=\left(w_{1}, w_{2}, \ldots, w_{m}\right)
$$

where $w_{i}=\rho_{i j} / \sum_{i=1}^{m} \rho_{i U}$.

Step 4. Calculate the combined weight. Calculate the combined weight $\theta=\left(\theta_{1}, \theta_{2}, \ldots, \theta_{m}\right)$; that is:

$$
\theta=\left[w_{1}, w_{2}, \cdots, w_{m}\right]\left[\begin{array}{cccc}
w_{11} & w_{12} & \cdots & w_{1 m} \\
w_{21} & w_{22} & \cdots & w_{2 m} \\
\vdots & \vdots & \ddots & \vdots \\
w_{m 1} & w_{m 2} & \cdots & w_{m m}
\end{array}\right]
$$

\subsubsection{Steps of the modified TOPSIS method}

The modified TOPSIS method is summarized as follows:

Step 1. Construct a normalized decision matrix $D$ :

$$
D=\left[\begin{array}{cccc}
r_{11} & r_{12} & \cdots & r_{1 n} \\
r_{21} & r_{22} & \cdots & r_{2 n} \\
\vdots & \vdots & \ddots & \vdots \\
r_{m 1} & r_{m 2} & \cdots & r_{m n}
\end{array}\right]
$$

where the normalized value $r_{i j}, i=1,2, \cdots, m, j=1,2, \cdots, n, x_{i j}$ is the $i$ th object in the $j$ th evaluation attribute of the original value (Eqs. (1) and (2)).

Step 2. Calculate attribute weights by combining weight methods (Eqs. (14)-(16)).

Step 3. Calculate the weighted normalized decision matrix $v=\left[v_{i j}\right]_{m \times n}$ :

$$
v_{i j}=w_{j} r_{i j}, i=1,2, \cdots, m, j=1,2, \cdots, n,
$$

where $w_{j}$ is the $j$ th attribute weighting value.

Step 4. Determine the positive ideal and negative ideal solution, $V^{+}$and $V^{-}$:

$$
V^{+}=\left\{v_{1}^{+}, v_{2}^{+}, \ldots, v_{n}^{+}\right\}=\left\{\left(\max _{i} v_{i j} \mid j \in J\right),\left(\min _{i} v_{i j} \mid j \in J^{\prime}\right)\right\},
$$




$$
V^{-}=\left\{v_{1}^{-}, v_{2}^{-}, \ldots, v_{n}^{-}\right\}=\left\{\left(\min _{i} v_{i j} \mid j \in J\right),\left(\max _{i} v_{i j} \mid j \in J^{\prime}\right)\right\},
$$

where $J$ is the index set of benefit attributes and $J^{\prime}$ is the index set of cost attributes. Step 5. Calculate the weighted Euclidean distances from the positive ideal solution $d_{i}^{+}$ (Eq. (6)), and the negative ideal solution $d_{i}^{-}$(Eq. (7)).

Step6. Calculate the relative closeness coefficient $C_{i}^{*}$ :

$$
C_{i}^{*}=\frac{d_{i}^{-}}{d_{i}^{+}+d_{i}^{-}}, i=1,2, \ldots, m,
$$

where $0 \leq C_{i}^{*} \leq 1$. The larger the $C_{i}^{*}$ value, the better the performance of the alternatives.

Step7. Rank the alternatives according to the relative closeness coefficient.

\section{Sample and data source}

Currently, in the CSR reports database site of Taiwan's Gretai Securities Market (GTSM), only 97 listed companies from different industries have disclosed their CSR reports. Therefore, this study selected 30 high-tech companies among these 97 companies in Taiwan as the research objects. In order to analyze the sustainable development performance evaluation and ranking of the 30 listed companies, this study uses 2011 financial ratios, CSR disclosure, R\&D intensity, environmental information disclosure, environmental intensity, and TCRI data as the evaluation indicator.

Among the evaluation indicator, the data of CSR reports are adopted from the database of the Business Council for Sustainable Development of Taiwan (BCSD-Taiwan) and the Taiwanese GTSM. For each company, environmental information disclosure, environmental intensity, R\&D intensity, TCRI and financial ratios data were retrieved from the TEJ database and annual report.

\section{Empirical analysis}

\subsection{The results of selecting representative financial indicators}

Table 1 shows the 22 financial ratios were divided into three main categories, operating ability, solvency and profitability, and the globalized GRA based grey entropy method is used to select the representative financial indicators. Because the value of the financial ratios may be positive or negative, so the first step of the GRA based grey entropy method is to normalize the data (data normalize between 0 and 1). Among the 22 financial ratios, the Day-A/R turnover and the Days-inventory turnover involved in the operating ability category and the liabilities involved in the solvency category are "the smaller-the-better" type indicators. The other 20 ratios are "the-larger-the-better" type indicators. The results of the normalization can be obtained according to Eqs (1) and (2). Then, we set the distinguishing coefficient as 0.5, and use Eq. (4) to calculate the grey relational coefficient. In order to improve the traditional globalized GRA, in accordance with Eqs. (8)-(11), this study calculates the entropy weight and substitutes it into Eq. 
(5) to obtain the grey relational matrix. The results are shown in Table 2. We set the threshold value as 0.7 to select the evaluation indicators from each category. Based on the results of Table 2, we present clustering results for each category, as shown in Table 3. The final results show that indicators $\mathrm{O} 1, \mathrm{O} 2, \mathrm{O} 5, \mathrm{O} 6$ and $\mathrm{O} 7$ are selected in the operating ability category, indicators S2, S6 and S9 are selected in the solvency category and indicators P2 and P6 are selected in profitability category (shown in Table3).

Table 2. The grey relational matrix of three categories

\begin{tabular}{|c|c|c|c|c|c|c|c|c|c|}
\hline \multicolumn{10}{|c|}{ Operating ability } \\
\hline & & O1 & $\mathrm{O} 2$ & $\mathrm{O} 3$ & $\mathrm{O} 4$ & O5 & O6 & O7 & \\
\hline & $\mathrm{O} 1$ & 1 & 0.6832 & 0.7324 & 0.7150 & 0.8205 & 0.6270 & 0.6574 & \\
\hline & $\mathrm{O} 2$ & 0.6723 & 1 & 0.6419 & 0.7328 & 0.7421 & 0.5386 & 0.6316 & \\
\hline & $\mathrm{O} 3$ & 0.7520 & 0.6792 & 1 & 0.6684 & 0.7638 & 0.6338 & 0.6589 & \\
\hline & $\mathrm{O} 4$ & 0.7043 & 0.7328 & 0.6319 & 1 & 0.8011 & 0.4992 & 0.5378 & \\
\hline & O5 & 0.8133 & 0.7431 & 0.7346 & 0.8020 & 1 & 0.5717 & 0.6020 & \\
\hline & O6 & 0.6213 & 0.5465 & 0.6013 & 0.5072 & 0.5778 & 1 & 0.6372 & \\
\hline & $\mathrm{O} 7$ & 0.6451 & 0.6316 & 0.6223 & 0.5378 & 0.6005 & 0.6297 & 1 & \\
\hline \multicolumn{10}{|c|}{ Solvency } \\
\hline & $\mathrm{S} 1$ & $\mathrm{~S} 2$ & S3 & S4 & S5 & S6 & S7 & S8 & S9 \\
\hline S1 & 1 & 0.6093 & 0.6584 & 0.6819 & 0.7599 & 0.8340 & 0.5145 & 0.5263 & 0.6329 \\
\hline $\mathrm{S} 2$ & 0.6182 & 1 & 0.7258 & 0.6965 & 0.5757 & 0.5796 & 0.6933 & 0.7137 & 0.7402 \\
\hline S3 & 0.6697 & 0.7269 & 1 & 0.9155 & 0.6570 & 0.6305 & 0.6510 & 0.6767 & 0.7861 \\
\hline S4 & 0.6927 & 0.6977 & 0.9155 & 1 & 0.6790 & 0.6435 & 0.6340 & 0.6540 & 0.7585 \\
\hline S5 & 0.7587 & 0.5623 & 0.6438 & 0.6666 & 1 & 0.7990 & 0.4975 & 0.5118 & 0.5977 \\
\hline S6 & 0.8337 & 0.5667 & 0.6163 & 0.6296 & 0.7990 & 1 & 0.4646 & 0.4824 & 0.5776 \\
\hline S7 & 0.5226 & 0.6916 & 0.6477 & 0.6307 & 0.5089 & 0.4761 & 1 & 0.9347 & 0.7069 \\
\hline S8 & 0.5216 & 0.7022 & 0.6627 & 0.6392 & 0.5102 & 0.4808 & 0.9314 & 1 & 0.7071 \\
\hline S9 & 0.6281 & 0.7290 & 0.7752 & 0.7465 & 0.5963 & 0.5761 & 0.6965 & 0.7071 & 1 \\
\hline \multicolumn{10}{|c|}{ Profitability } \\
\hline & & P1 & $\mathrm{P} 2$ & P3 & P4 & P5 & P6 & & \\
\hline & $\mathrm{P} 1$ & 1 & 0.6794 & 0.6501 & 0.7582 & 0.8462 & 0.8527 & & \\
\hline & $\mathrm{P} 2$ & 0.5891 & 1 & 0.8905 & 0.6168 & 0.6057 & 0.6029 & & \\
\hline & P3 & 0.5367 & 0.8841 & 1 & 0.5787 & 0.5710 & 0.5535 & & \\
\hline & $\mathrm{P} 4$ & 0.6690 & 0.6016 & 0.5787 & 1 & 0.6931 & 0.7245 & & \\
\hline & P5 & 0.8274 & 0.6631 & 0.6470 & 0.7573 & 1 & 0.9127 & & \\
\hline & P6 & 0.8323 & 0.6561 & 0.6279 & 0.7801 & 0.9114 & 1 & & \\
\hline
\end{tabular}


Table 3. The classification financial ratios and select the representative indicators

\begin{tabular}{|c|c|c|c|}
\hline Categories & Groups & Indicators within each group & Representative indicator of each group \\
\hline \multirow{5}{*}{$\begin{array}{l}\text { Operating } \\
\text { ability }\end{array}$} & G1 & $\mathrm{O} 1, \mathrm{O} 4$ & O1: Total assets turnover ratio \\
\hline & G2 & $\mathrm{O} 2, \mathrm{O} 3$ & O2: Accounts receivable turnover \\
\hline & G3 & $\mathrm{O5}$ & O5: Turnover of networth \\
\hline & G4 & O6 & O6: Days-A/R turnover \\
\hline & G5 & $\mathrm{O} 7$ & O7: Days-inventory turnover \\
\hline \multirow[t]{3}{*}{ Solvency } & G6 & $\mathrm{S} 1, \mathrm{~S} 4, \mathrm{~S} 5, \mathrm{~S} 6, \mathrm{~S} 7$ & S6: Times interest earned \\
\hline & G7 & $\mathrm{S} 2, \mathrm{~S} 3, \mathrm{~S} 8$ & S2: Cash reinvestment ratio \\
\hline & G8 & S9 & S9: Liabilities \\
\hline \multirow[t]{2}{*}{ Profitability } & G9 & P2, P3, P4 & P2: Return on equity \\
\hline & G10 & P1, P5, P6 & P6: Earnings per share \\
\hline
\end{tabular}

\subsection{The empirical results of the modified TOPSIS method}

In this study, first make sure that the object $i$ is 30 high-tech companies in Taiwan (company $\mathrm{C} 1$ to $\mathrm{C} 30$ ). The evaluation attribute $j$ stands for 15 sustainable development performance evaluation indicators. The step-by-step instructions for the opening process are as follows.

Step 1. Construct the normalized decision matrix. Among the 10 representative financial ratios, Day-A/R turnover, Days-inventory turnover and liabilities are "the smaller-thebetter" type indicators, while the rest of the ratios are the larger-the-better. Therefore, using Eqs. (1) and (2), we can get the normalized decision matrix $D_{30 \times 15}$ :

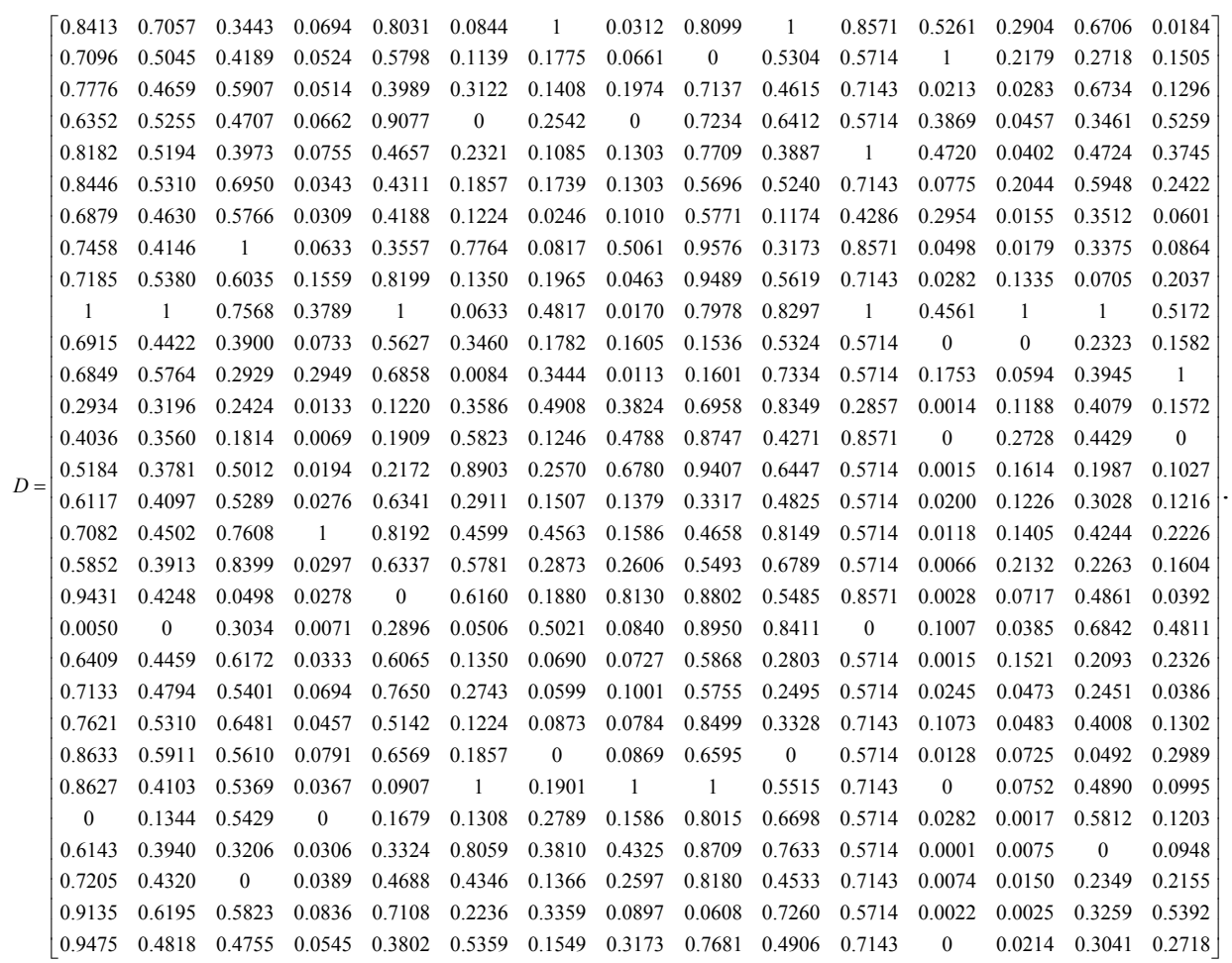


Step 2. This study uses the Spearman rank correlation coefficient objective weighting method to obtain the combined weight by applying the grey entropy method, grey relational matrix method and CRITIC method, as follows:

(1) Results of the grey relational matrix method: The grey relational matrix is calculated based on Eqs. (1)-(5), as shown in Table 4. Then, by calculating the eigenvalue and eigenvector of the matrix, the largest eigenvalue we can obtain is $\lambda_{\max }=9.8754$. Finally, find the eigenvector that corresponds to the largest eigenvalue and normalize to 1 . We can get the weight of the grey relational matrix method, as shown in Table 5 . Of which, indicators CSRD (0.0710), S2 (0.0707) and M2 (0.0706) are the three most important variables affecting companies' sustainable development performance.

(2) Results of the CRITIC method: The objective weight of 15 sustainable development performance evaluation indicators can be calculated according to Eqs (12) and (13), as shown in Table 5. Table 5 shows the objective weight results when using the CRITIC method, and the indicators M1 (0.0949), M6 (0.0917) and M5 (0.0864) are the three most important variables affecting the sustainable performance of a company.

(3) Results of the grey entropy method: Substituting Eq. (22) into (10) and (11), we obtain the entropy weight of the 15 sustainable development performance evaluation indicators, as shown in Table 5. The results show that the indicators S6 (0.0691), Envint (0.0688) and Envd (0.068) are the three most important variables affecting the sustainability performance of a company.

(4) Results of the Spearman rank correlation coefficient objective weighting method: Based on the weight values obtained by the grey entropy method, grey relational matrix method and CRITIC method from Table 5, this study ranks and calculates the Spearman rank correlation coefficient matrix between the three methods, as shown in Table 6 . First calculate the average degree of consistency from Table $6, \rho_{1 U}=(0.268+0.357) / 2=0.3125$, $\rho_{2 U}=(0.268+0.114) / 2=0.1911, \quad \rho_{3 U}=(0.357+0.114) / 2=0.2357$. Then normalizing it to lie between zero and one, we can get $w_{1}=0.4227, w_{2}=0.2585$, and $w_{3}=0.3188$, and substituting into Eq. (16) we obtain:

$$
\theta=[0.4227,0.2585,0.3188]\left[\begin{array}{llll}
0.0665 & 0.0407 & \cdots & 0.0703 \\
0.0635 & 0.0406 & \cdots & 0.0671 \\
0.0659 & 0.0656 & \cdots & 0.0667
\end{array}\right]_{3 \times 15} .
$$

Finally, the combined weights of the 15 sustainable development evaluation indicators can be calculated, as shown in Table 5. The results show that the indicators CSRD (0.07482), M1 (0.07476) and S9 (0.0701) are the three most important variables affecting the sustainability performance of a company.

Table 5 shows that the results of the ranking determined by three weight methods are quite different. However, the ranking results of the proposed combined weight method are quite different than those of the grey relational matrix method and grey entropy method, but similar to the CRITIC method, with a Spearman rank correlation coefficient of $0.975(\mathrm{p}<0.01)$. 
Table 4. The grey relational matrix of evaluation criteria

\begin{tabular}{|c|c|c|c|c|c|c|c|c|c|c|c|c|c|c|c|}
\hline & $\mathrm{P} 2$ & P6 & $\mathrm{S} 2$ & S6 & S9 & M1 & M2 & M5 & M6 & M7 & TCRI & EID & EI & CSRD & RDI \\
\hline $\mathrm{P} 2$ & 1 & 0.704 & 0.671 & 0.473 & 0.707 & 0.579 & 0.504 & 0.714 & 0.679 & 0.648 & 0.817 & 0.482 & 0.505 & 0.581 & 0.502 \\
\hline P6 & 0.702 & 1 & 0.745 & 0.551 & 0.777 & 0.655 & 0.635 & 0.598 & 0.628 & 0.736 & 0.754 & 0.574 & 0.599 & 0.737 & 0.633 \\
\hline $\mathrm{S} 2$ & 0.678 & 0.753 & 1 & 0.577 & 0.737 & 0.603 & 0.617 & 0.598 & 0.652 & 0.694 & 0.743 & 0.581 & 0.590 & 0.675 & 0.628 \\
\hline S6 & 0.483 & 0.564 & 0.578 & 1 & 0.575 & 0.667 & 0.769 & 0.448 & 0.485 & 0.541 & 0.483 & 0.833 & 0.843 & 0.631 & 0.772 \\
\hline S9 & 0.706 & 0.778 & 0.730 & 0.565 & 1 & 0.571 & 0.611 & 0.663 & 0.597 & 0.708 & 0.706 & 0.583 & 0.596 & 0.653 & 0.641 \\
\hline M1 & 0.591 & 0.667 & 0.607 & 0.669 & 0.584 & 1 & 0.688 & 0.487 & 0.639 & 0.662 & 0.614 & 0.610 & 0.685 & 0.672 & 0.668 \\
\hline M2 & 0.512 & 0.645 & 0.617 & 0.768 & 0.619 & 0.685 & 1 & 0.521 & 0.548 & 0.633 & 0.544 & 0.722 & 0.767 & 0.731 & 0.794 \\
\hline M5 & 0.723 & 0.613 & 0.602 & 0.450 & 0.675 & 0.487 & 0.525 & 1 & 0.649 & 0.641 & 0.666 & 0.469 & 0.471 & 0.567 & 0.506 \\
\hline M6 & 0.689 & 0.641 & 0.656 & 0.488 & 0.609 & 0.639 & 0.552 & 0.649 & 1 & 0.642 & 0.744 & 0.494 & 0.505 & 0.630 & 0.518 \\
\hline M7 & 0.656 & 0.744 & 0.694 & 0.539 & 0.715 & 0.659 & 0.633 & 0.637 & 0.638 & 1 & 0.684 & 0.540 & 0.555 & 0.721 & 0.612 \\
\hline TCRI & 0.818 & 0.758 & 0.740 & 0.477 & 0.709 & 0.605 & 0.538 & 0.658 & 0.738 & 0.680 & 1 & 0.488 & 0.508 & 0.641 & 0.530 \\
\hline EID & 0.494 & 0.589 & 0.584 & 0.834 & 0.596 & 0.610 & 0.725 & 0.469 & 0.494 & 0.544 & 0.498 & 1 & 0.809 & 0.662 & 0.748 \\
\hline EI & 0.512 & 0.610 & 0.590 & 0.842 & 0.604 & 0.681 & 0.767 & 0.467 & 0.501 & 0.556 & 0.513 & 0.806 & 1 & 0.688 & 0.773 \\
\hline CSRD & 0.578 & 0.737 & 0.665 & 0.620 & 0.651 & 0.660 & 0.723 & 0.553 & 0.617 & 0.713 & 0.636 & 0.649 & 0.679 & 1 & 0.684 \\
\hline RDIt & 0.513 & 0.646 & 0.630 & 0.773 & 0.651 & 0.667 & 0.795 & 0.504 & 0.516 & 0.614 & 0.538 & 0.747 & 0.774 & 0.695 & 1 \\
\hline
\end{tabular}

Table 5. Weight of criteria by four methods

\begin{tabular}{lcccccccc}
\hline \multirow{2}{*}{$\begin{array}{l}\text { Grey } \\
\text { relational }\end{array}$} & P2 & P6 & S2 & S6 & S9 & M1 & M2 & M5 \\
\cline { 2 - 10 } $\begin{array}{l}\text { matrix } \\
\text { method }\end{array}$ & 0.0665 & 0.0407 & 0.0707 & 0.0674 & 0.0705 & 0.0687 & 0.0706 & 0.0627 \\
\cline { 2 - 10 } & M6 & M7 & TCRI & EID & EI & CSRD & RDI & \\
\hline & 0.0657 & 0.0700 & 0.0689 & 0.0673 & 0.0692 & 0.0710 & 0.0703 & \\
\cline { 2 - 10 } & P2 & P6 & S2 & S6 & S9 & M1 & M2 & M5 \\
\cline { 2 - 10 } $\begin{array}{l}\text { CRITIC } \\
\text { method }\end{array}$ & 0.0635 & 0.0406 & 0.0661 & 0.0612 & 0.0743 & 0.0949 & 0.0599 & 0.0864 \\
\cline { 2 - 10 } & M6 & M7 & TCRI & EID & EI & CSRD & RDI & \\
\hline \multirow{4}{*}{$\begin{array}{l}\text { Grey } \\
\text { entropy } \\
\text { method }\end{array}$} & 0.0917 & 0.0687 & 0.0510 & 0.0694 & 0.0457 & 0.0596 & 0.0671 & \\
\cline { 2 - 10 } & P2 & P6 & S2 & S6 & S9 & M1 & M2 & M5 \\
\hline & 0.0655 & 0.0657 & 0.0658 & 0.0688 & 0.068 & 0.0662 & 0.0667 & \\
\hline $\begin{array}{l}\text { Combined } \\
\text { weight } \\
\text { method }\end{array}$ & 0.0655 & 0.0486 & 0.0680 & 0.0663 & 0.0701 & 0.07476 & 0.0665 & 0.0697 \\
\cline { 2 - 9 } & M6 & M7 & TCRI & EID & EI & CSRD & RDI & \\
\hline & 0.0641 & 0.0683 & 0.0633 & 0.0683 & 0.0627 & 0.07482 & 0.0683 & \\
\hline
\end{tabular}


Table 6. Spearman rank correlation coefficient matrix

\begin{tabular}{lccc}
\hline & $\begin{array}{c}\text { Grey relational } \\
\text { matrix method }\end{array}$ & $\begin{array}{c}\text { CRITIC } \\
\text { method }\end{array}$ & $\begin{array}{c}\text { Grey entropy } \\
\text { method }\end{array}$ \\
\hline Grey relational matrix method & 1 & 0.268 & 0.357 \\
\hline CRITIC method & 0.268 & 1 & 0.114 \\
\hline Grey entropy method & 0.357 & 0.114 & 1 \\
\hline
\end{tabular}

Step 3. Determine the positive ideal and negative ideal solutions, $V^{+}$and $V^{-}$. In this study, $V^{+}=[1,1, \cdots, 1]_{1 \times 15}$ and $V^{-}=[0,0, \cdots, 0]_{1 \times 15}$.

Step 4. Calculate the weighted Euclidean distances from the positive ideal solution $d_{i}^{+}$ (Eq. (13)), and the negative ideal solution $d_{i}^{-}$; the results are shown in Table 7.

Step 5. Calculate the relative closeness coefficient $C_{i}^{*}$; the results are shown in Table 7.

Step 6. Table 7 shows the sustainable development performance ranking results for 30 listed high-tech companies in Taiwan. The sustainability performance ranking of the top five of the 30 companies is C10, C20, C24, C19 and C26. That is, these five companies are associated with better sustainability performance among the 30 companies. For a fund manager or investor who wants to choose among 30 companies, these five companies can be selected as priority investment targets. The performance of the worst five are ranked as follows: $\mathrm{C} 8, \mathrm{C} 15, \mathrm{C} 18, \mathrm{C} 27$ and $\mathrm{C} 17$. That is, these five companies with poor performance on sustainable development should be avoided by those considering investment targets.

Table 7. The results of modified TOPSIS method

\begin{tabular}{cccccccccc}
\hline Company & $d_{i}^{*}$ & $d_{i}^{-}$ & $C_{i}^{*}$ & Rank & Company & $d_{i}^{*}$ & $d_{i}^{-}$ & $C_{i}^{*}$ & Rank \\
\hline C1 & 0.5898 & 0.0301 & 0.0486 & 10 & C16 & 0.7161 & 0.0340 & 0.0453 & 22 \\
\hline C2 & 0.7035 & 0.0354 & 0.0479 & 12 & C17 & 0.5732 & 0.0244 & 0.0408 & 30 \\
\hline C3 & 0.6764 & 0.0323 & 0.0456 & 21 & C18 & 0.6473 & 0.0289 & 0.0428 & 28 \\
\hline C4 & 0.6588 & 0.0344 & 0.0497 & 7 & C19 & 0.6991 & 0.0371 & 0.0504 & 4 \\
\hline C5 & 0.6463 & 0.0300 & 0.0444 & 24 & C20 & 0.7709 & 0.0438 & 0.0537 & 2 \\
\hline C6 & 0.6578 & 0.0329 & 0.0477 & 13 & C21 & 0.7334 & 0.0379 & 0.0492 & 8 \\
\hline C7 & 0.7534 & 0.0375 & 0.0474 & 14 & C22 & 0.7336 & 0.0355 & 0.0462 & 20 \\
\hline C8 & 0.6559 & 0.0298 & 0.0435 & 26 & C23 & 0.7062 & 0.0356 & 0.0480 & 11 \\
\hline C9 & 0.6900 & 0.0337 & 0.0466 & 18 & C24 & 0.7551 & 0.0403 & 0.0507 & 3 \\
\hline C10 & 0.4703 & 0.0271 & 0.0544 & 1 & C25 & 0.6416 & 0.0316 & 0.0470 & 17 \\
\hline C11 & 0.7342 & 0.0343 & 0.0447 & 23 & C26 & 0.7655 & 0.0405 & 0.0502 & 5 \\
\hline C12 & 0.6711 & 0.0353 & 0.0500 & 6 & C27 & 0.6933 & 0.0295 & 0.0409 & 29 \\
\hline C13 & 0.7205 & 0.0351 & 0.0464 & 19 & C28 & 0.7233 & 0.0359 & 0.0473 & 15 \\
\hline C14 & 0.7078 & 0.0350 & 0.0471 & 16 & C29 & 0.6821 & 0.0349 & 0.0487 & 9 \\
\hline C15 & 0.6620 & 0.0301 & 0.0435 & 27 & C30 & 0.6644 & 0.0304 & 0.0438 & 25 \\
\hline
\end{tabular}




\subsection{Sensitivity analysis}

We follow the idea of Moghassem (2013) and decrease and increase the combined weights for the top three evaluation criteria of $10 \%$ (we do not change the ranking of 15 evaluation criteria), and then use the modified TOPSIS method to calculate the ranking and analysis of its sensitivity. We take small changes in weight to understand the impact on the results of performance ranking. The results can be used as a basis for a company to examine whether the performance evaluation ranking is reliable. The results of the increase and decrease in weight of the modified TOPSIS method are shown in Table 8. In this study, we compare the results of performance ranking between Table 7 and Table 8 by using a Spearman rank correlation coefficient test. The results shows that according to the Spearman rank correlation coefficient, the increase and decrease of weight for the modified TOPSIS method were $0.981(\mathrm{p}<0.01)$ and $0.993(\mathrm{p}<0.01)$, respectively. This shows that with a small variation in the combined weights, the sustainable development performance ranking of the 30 companies do not change significantly.

Table 8. The results of sensitivity analysis

\begin{tabular}{cccccccc}
\hline \multicolumn{3}{c}{ Increase in weight method } & \multicolumn{5}{c}{ Decrease in weight method } \\
\hline Company & Rank & Company & Rank & Company & Rank & Company & Rank \\
\hline C1 & 8 & C16 & 22 & C1 & 11 & C16 & 22 \\
\hline C2 & 12 & C17 & 30 & C2 & 10 & C17 & 30 \\
\hline C3 & 21 & C18 & 28 & C3 & 21 & C18 & 28 \\
\hline C4 & 4 & C19 & 5 & C4 & 8 & C19 & 5 \\
\hline C5 & 23 & C20 & 2 & C5 & 24 & C20 & 1 \\
\hline C6 & 13 & C21 & 9 & C6 & 13 & C21 & 7 \\
\hline C7 & 14 & C22 & 20 & C7 & 16 & C22 & 19 \\
\hline C8 & 27 & C23 & 10 & C8 & 26 & C23 & 12 \\
\hline C9 & 16 & C24 & 7 & C9 & 20 & C24 & 4 \\
\hline C10 & 1 & C25 & 15 & C10 & 2 & C25 & 17 \\
\hline C11 & 24 & C26 & 6 & C11 & 23 & C26 & 3 \\
\hline C12 & 3 & C27 & 29 & C12 & 6 & C27 & 29 \\
\hline C13 & 17 & C28 & 19 & C13 & 18 & C28 & 15 \\
\hline C14 & 18 & C29 & 11 & C14 & 14 & C29 & 9 \\
\hline C15 & 25 & C30 & 26 & C15 & 27 & C30 & 25 \\
\hline & & & & & & & \\
\hline
\end{tabular}




\section{Conclusions}

In this study, we first create a globalized GRA based grey entropy method by clustering to select 10 representative financial ratios among 22 financial ratios. And then we combine credit risk and four sustainability performance indicators, making a total of 15 indicators within the sustainability performance evaluation criteria. Finally, we propose a modified TOPSIS method for sustainability performance evaluation and ranking of 30 listed high-tech companies in Taiwan. The main results are as follow: 1) the results of the three weights models based on grey entropy method, grey relational matrix method and CRITIC method are significantly different; 2) The result of proposed combined weight method is similar with the CRITIC method, but the results of the other two methods are quite different; 3 ) The results of the modified TOPSIS method show that among the 30 listed high-tech companies in Taiwan in 2011, the performance ranking of the top five of the 30 companies is C10, C20, C24, C19 and C26. The sustainability performance ranking of the worst five is C8, C15, C18, C27 and C17; 4) Sensitivity analysis results show that the proposed modified TOPSIS method is stable and reliable for performance ranking.

The empirical results of this study will help fund managers or general investors to choose investment targets. Therefore, investors facing numerous investment instruments can calculate performance ranking based on the proposed model, and choose the top ranked companies as investment targets. This ensures that a company can achieve sustainable development and reduce risk, and, thereby ensure profitability.

\section{Acknowledgement}

The authors would like to thank the National Science Council of the Republic of China, Taiwan for financially supporting this research under Contract No. NSC 102-2410-H275-010.

\section{References}

Alam, H.; Raza, A.; Akram, M. 2011. Financial performance of leasing sector. The case of Pakistan, Interdisciplinary Journal of Contemporary Research in Business 2(12): 339-345.

Arshad, R.; Mansor, S. M.; Othman, R. 2012. Market orientation, firm performance and the mediating effect of corporate social responsibility, Journal of Applied Business Research 28(5): 851-860 [online], [cited 22 April 2013]. Available from Internet: http://cluteinstitute.com/ojs/ index.php/JABR/article/download/7228/7298-288521-1-PB.pdf

Behzadian, M.; Khanmohammadi Otaghsara, S.; Yazdani, M.; Ignatius, J. 2012. A state-of the-art survey of TOPSIS applications, Expert Systems with Applications 39(17): 13051-13069.

http://dx.doi.org/10.1016/j.eswa.2012.05.056

Çetin, M. K.; Çetin, E. I. 2010. Multi-criteria analysis of banks' performances, International Journal of Economics and Finance Studies 2(2): 73-78.

Cheng, C. H.; Chen, C. T.; Huang, S. F. 2012. Combining fuzzy integral with order weight average (OWA) method for evaluating financial performance in the semiconductor industry, African Journal of Business Management 6(21): 6358-6368. http://dx.doi.org/10.5897/AJBM11.534 
Choi, F. D. S.; Mueller, G. G. 1992. What is coefficient alpha? An examination of theory and application, Journal of Applied Psychology 78(2): 98-104.

http://dx.doi.org/10.1037/0021-9010.78.1.98

Diakoulaki, D.; Mavrotas, G.; Papayannakis, L. 1995. Determining objective weights in multiple criteria problems: the critic method, Computers \& Operations Research 22(7): 763-770.

http://dx.doi.org/10.1016/0305-0548(94)00059-H

Elkington, J. 1997. Cannibals with forks: the triple bottom line of twenty first century business. Oxford: Capstone.

Eshlaghy, A. T.; Kalantary, M. 2011. Supplier selection by Neo-TOPSIS, Applied Mathematical Sciences 5(17): 837-844 [online], [cited 25 March 2013]. Available from Internet: http://www.mhikari.com/ams/ams-2011/ams-17-20-2011/lotfiAMS17-20-2011-4.pdf

Gamble, R. H. 1989. A history of the Federal Reserve Bank of Atlanta, 1914-1989. Federal Reserve Bank Atlanta.

Hsu, L. C. 2014. Using a decision-making process to evaluate efficiency and operating performance for listed semiconductor companies, Technological and Economic Development of Economy. http://dx.doi.org/10.3846/20294913.2013.876689

Lu, S. L. 2012. Assessing the credit risk of bank loans using an extended Markov chain model, Journal of Applied Finance \& Banking 2(1): 197-223 [online], [cited 28 March 2013]. Available from Internet: http://www.scienpress.com/Upload/JAFB/Vol\%202_1_9.pdf

Moghassem, A. 2013. Comparison among two analytical methods of multi-criteria decision making for appropriate spinning condition selection, World Applied Sciences Journal 21(5): 784-794.

Olson, D. 2004. Comparison of weights in TOPSIS models, Mathematical and Computer Modelling 40(7): 721-727. http://dx.doi.org/10.1016/j.mcm.2004.10.003

Ozturkoglu, Y.; Turker, D. 2013. Application of TOPSIS to analyze stakeholder relations, International Journal of Business and Social Research 3(5): 245-255 [online], [cited 18 March 2013]. Available from Internet: http://thejournalofbusiness.org/index.php/site/article/download/23/22

Ratanajongkol, S.; Davey, H.; Low, M. 2006. Corporate social reporting in Thailand: the news is all good and increasing, Qualitative Research in Accounting \& Management 3(1): 67-83.

http://dx.doi.org/10.1108/11766090610659751

Seçme, N. Y.; Bayrakdaroğlu, A.; Kahraman, C. 2009. Fuzzy performance evaluation in Turkish banking sector using analytic hierarchy process and TOPSIS, Expert Systems with Applications 36(9): 11699-11709. http://dx.doi.org/10.1016/j.eswa.2009.03.013

Shyur, H. J.; Shih, H. S. 2006. A hybrid MCDM model for strategic vendor selection, Mathematical and Computer Modelling 44(7): 749-761. http://dx.doi.org/10.1016/j.mcm.2005.04.018

Suh, Y. J.; You, J. J.; Kim, P. S. 2013. The effect of innovation capabilities and experience on cross-border acquisition performance, Global Journal of Business Research 7(3): 59-74 [online], [cited 20 March 2013]. Available from Internet: http://ssrn.com/abstract=2148551

Suttipun, M.; Stanton, P. 2012. Determinants of environmental disclosure in Thai corporate annual reports, International Journal of Accounting and Financial Reporting 2(1): 99-115.

http://dx.doi.org/10.5296/ijafr.v2i1.1458

Yalçin, N.; Bayrakdaroglu, A.; Kahraman, C. 2012. Application of fuzzy multi-criteria decision making methods for financial performance evaluation of Turkish manufacturing industries, Expert Systems with Applications 39(1): 350-364. http://dx.doi.org/10.1016/j.eswa.2011.07.024

Yoon, K. P.; Hwang, C. L. 1995. Multiple attribute decision making: an introduction. Thousand Oaks: Sage Publications.

Zeng, L.; Benatallah, B.; Ngu, A. H. H., Dumas, M.; Kalagnanam, J.; Chang, H. 2004. QoSaware middleware for web services composition, Software Engineering, IEEE Transactions on Software Engineering 30(5): 311-327. http://dx.doi.org/10.1109/TSE.2004.11 
Li-Chang HSU is a Professor of economics at Ling Tung University, in Taiwan. His research areas are decision-making theory and practice, grey system theory and technology management. His articles are published by Journal of Business Economics and Management, Technological and Economic Development of Economy, British Journal of Management, Technological Forecasting and Social Change, Expert Systems with Application, Service Business, Journal of Electronic Commerce Research and others.

Shang-Ling OU is an Assistant Professor of biostatistics in the Department of Agronomy, National Chung Hsing University, Taiwan. Her research areas are statistical genetics, yield prediction, experimental design, grey system theory and fuzzy measure. Her articles are published by Computers and Electronics in Agriculture, Plant Breeding, Journal of Applied Statistics and others.

Yih-Chang OU is an Assistant Professor of statistics at Ling Tung University, Taiwan. His research areas are generalized linear model, risk management, investment management and biometry. His articles are published by Journal of Applied Statistics, International Journal of Economics and Finance, International Business Research and others. 